Int. J. Electrochem. Sci., 14 (2019) $4852-4860$

\title{
Determination of Gallic Acid in Tea by a Graphene Modified Glassy Carbon Electrode
}

\author{
Meifeng Chen, Huiping Lv, Xia Li, Zhilong Tian, Xinying $M a^{*}$ \\ College of Chemistry and Chemical Engineering, Heze University, Shandong, Heze274015, China \\ *E-mail: hezexueyuanhx@163.com
}

doi: $10.20964 / 2019.05 .23$

Received: 24 December 2018 / Accepted: 21 February 2019 / Published: 10 April 2019

The determination of gallic acid (GA) content by a graphene modified glassy carbon electrode (graphene/GCE) was studied. The electrochemical behavior of GA on this electrode was studied by cyclic voltammetry $(\mathrm{CV})$, and the standard curve was constructed by differential pulse voltammetry (DPV). The results indicate that graphene has a good catalytic effect on GA in phosphate buffer (PBS) and shows a linear response toward GA in the $8.0 \times 10^{-8}$ to $2.0 \times 10^{-5} \mathrm{~mol} \cdot \mathrm{L}^{-1}$ concentration range. The detection limit is $1.2 \times 10^{-9} \mathrm{~mol} \cdot \mathrm{L}^{-1}$. This proposed determination for GA on graphene/GCE was carried out in the presence of potentially interfering compounds such as sorbic acid, tartaric acid, ascorbic acid and glucose. The content of GA in green tea was determined by this method, and the recovery was $97.9 \%$ $-100.6 \%$ with satisfactory results.

Keywords: Gallic acid; Differential pulse voltammetry; Graphene; Electrochemical determination

\section{$\underline{\text { FULL TEXT }}$}

(C) 2019 The Authors. Published by ESG (www.electrochemsci.org). This article is an open access article distributed under the terms and conditions of the Creative Commons Attribution license (http://creativecommons.org/licenses/by/4.0/). 